\title{
When Green Infrastructure Turns Grey: Implications of Overdesign on Plant Water Stress
}

\author{
Min-cheng Tu 1,3, Joshua S. Caplan 2,", Sasha W. Eisenman ${ }^{2}$, Bridget M. Wadzuk ${ }^{1}$ \\ 1 Department of Civil and Environmental Engineering, Villanova University, Villanova, Pennsylvania, USA \\ 19085 \\ 2 Department of Architecture and Environmental Design, Temple University, Ambler, Pennsylvania, USA \\ 19002 \\ 3 Department of Civil Engineering, National Taipei University of Technology, Taipei City, Taiwan \\ * Correspondence: jcaplan@temple.edu
}

\begin{abstract}
Green infrastructure systems are often overdesigned. This may be a byproduct of static sizing (e.g., accounting for a design storm's runoff volume but not exfiltration rates) or may be deliberate (e.g., buffering against performance loss through time). Regardless, overdesign may compromise plants' access to water in systems where soil pits are embedded in infiltration beds. It could raise the storm size required for water to reach soil pits, reducing water availability between storms, which could ultimately induce plant physiological stress. This study investigated the hydrological dynamics and water relations of a tree trench system suspected to have been overbuilt and identified factors contributing to, compounding, and mitigating the risk of plant stress. Results provided strong evidence that the abovementioned processes played out. Water in the infiltration bed reached soil pits only once in three years, with that event occurring during a hydrant release. Moreover, minimal water was retained in the soil pit during the event due to the hydraulic properties of the soil media. Through a growing season, one of the two tree types frequently experienced water stress, while the other did so only rarely. These contrasting responses can likely be attributed to roots either being largely confined to the soil pits or reaching a deeper water source. Implications of these results for green infrastructure design are considered.
\end{abstract}

Keywords: evapotranspiration; green infrastructure; HYDRUS; leaf water potential; low impact development; optimization; overdesign; stomatal conductance; simulated runoff test; static sizing; stormwater control measure; tree trench

\section{Introduction}

The use of green infrastructure (GI) to control non-point pollution associated with stormwater has been written into law by municipalities around the world [1-3]. Such laws protect surface water bodies in and adjacent to urban areas from contaminants transported by stormwater as well as those released during combined sewer overflow events [4]. By reducing the volume of stormwater entering combined sewer systems, GI lowers pollutant loading, runoff velocity, and peak flow rates [5]. Although GI systems need not be vegetated, plants and soils can contribute substantially to volume reduction, in particular by enhancing rates of evapotranspiration (ET), interception, and infiltration [6-9]. Evapotranspiration is arguably the most effective of these processes with respect to volume reduction; studies using weighing lysimeters have found that $50 \%$ of incident precipitation can be removed by ET [10-15]. Moreover, vegetated GI systems provide additional ecosystem services such as improving air quality and cooling the local environment, thereby promoting human health [16].

Many GI systems are overdesigned, i.e., built larger than required, which can be done for a variety of reasons. It can be deliberate, e.g., to ensure that not only is a design goal achieved but that there is a margin for performance degradation due to sedimentation or increasing storm sizes in the 
future. It can also be unintended, e.g., when a system is sized to meet a static guideline (such as a design storm volume) without accounting for the rate of exfiltration. Nonetheless, overdesign is generally considered benign to stormwater control performance and is often favored [17]. However, there is some evidence that overdesign can have negative implications for plant water availability in systems designed to use stormwater as the primary water source for vegetation [18]. For plants that have limited access to alternative water sources between storms, overdesign may increase the frequency, intensity, and duration of plant water stress events, ultimately reducing their transpiration rates and diminishing the associated benefits.

Any implications of overdesign for GI hydrology and plant water stress are likely to be influenced by plants' biological characteristics. For example, woody plants in overdesigned systems may experience water shortages more rapidly after storms compared to herbaceous species given their greater canopy-scale transpiration rates [19]. However, there may also be considerable differences among species within a given functional type. For example, variation in the size, architecture, or morphology of root systems is known to influence access to water and transpiration responses to varying soil moisture regimes [20-21], suggesting that these factors may influence water relations in overdesigned GI systems.

A number of physiological measurements can provide insight into plant water relations, including stress responses, though they have been used infrequently to evaluate GI systems. Transpiration (i.e., the efflux of water from a leaf or canopy) can be measured or estimated with a variety of methods, though many cannot differentiate transpiration from evaporation from soil; the combined flux of water via ET is therefore used frequently. Moreover, while transpiration (or ET) plays a large role in the water balance of GI systems, transpiration is influenced by atmospheric conditions and is therefore only loosely indicative of plant water stress. In contrast, stomatal conductance $\left(\mathrm{g}_{\mathrm{s}}\right)$ is a metric that directly reflects the component of water release influenced by plants themselves; $g_{s}$ can be considered transpiration normalized to the evaporative demand of the atmosphere (specifically the vapor pressure gradient between the leaf and the air [22]). Values below approximately $150 \mathrm{mmol} \mathrm{m}^{-2} \mathrm{~s}^{-1}$ under well-lit conditions are often indicative of water stress in temperate woody species, though this is highly variable [23]. Perhaps the most reliable measure of water stress is the potential (i.e., tension) of water in plant tissue, with measurements made on leaves when they are at their daily minimum near mid-day $\left(\Psi_{\mathrm{md}}\right)$ being the most commonly used. Values below -1.5 MPa typically indicates a stressed state in species that are intolerant of drought or saline soils [22].

A series of investigations was carried out to probe the dynamics of a tree trench suspected to have been inadvertently overbuilt. Tree trenches are a type of GI in which one or more tree/soil pits are embedded in a gravel-filled catchment. Stormwater is intended to enter the soil pits from below, such that these systems could be subject to hydrological limitation if overdesigned. This study had four objectives, each of which was addressed through a distinct investigation:

1. Confirm with hydrological data that the tree trench was overbuilt. This was done by determining the frequency that the stormwater level in the trench intercepted soil pits.

2. Characterize the response of tree water relations to varying soil moisture conditions and determine how this response differed between species. This was done by evaluating how leaf water potential and stomatal conductance changed for two species in response to variation in soil moisture conditions throughout a growing season.

3. Determine how soil moisture levels and tree water use respond to an extremely large storm event, i.e., the best-case scenario with respect to stormwater delivery to soil pits if the system is overdesigned. To achieve this, a simulated runoff test was conducted in the focal system simultaneous with repeated measurements of stomatal conductance.

4. Evaluate how the composition of media in the soil pits influences the soil moisture response to wetting by the infiltration bed. This was done using a 2D unsaturated zone hydrologic model of a soil pit that was parameterized with empirical measurements of the soil's hydraulic properties and the time series of water elevation in the infiltration bed during the simulated runoff test.

\section{Materials and Methods}




\subsection{Site description}

This study focused on a GI tree trench located in northwest Philadelphia, USA, at $40.070^{\circ} \mathrm{N}$, $75.175^{\circ} \mathrm{W}$. The tree trench was constructed in 2013 and is composed of a gravel-filled infiltration bed installed beneath a sidewalk. Five trees and their associated soil pits (numbered T1 to T5) are embedded in the gravel bed (Fig. 1). The soil pits contain an engineered sandy soil $(87.6 \%$ sand, $8.2 \%$ silt, $4.2 \%$ clay) surrounded with geotextile. The trees in T1, T3, and T5 are Plantanus $\times$ acerifolia 'Bloodgood' (London plane tree) while those in T2 and T4 are Acer $\times$ freemanii 'Armstrong' (Freeman's maple). The bottom of the infiltration bed is lined with a layer of sand $15 \mathrm{~cm}$ thick. Approximately $2,494 \mathrm{~m}^{2}$ of road surface area drains to the trench, yielding an 11.8:1 ratio of directly-connected impervious area to treatment bed area. Two inlet structures (GI1 and GI2) collect runoff water from the street and a perforated distribution pipe delivers water collected by the inlet structures into the infiltration bed. The system was sized statically, specifically so that a $4.75 \mathrm{~cm}$ storm could be contained in the media's void space (Chris Bergerson, Philadelphia Water Department, pers. comm.). Given that static sizing was used, it was a strong candidate for having been overbuilt. Runoff entering the bottom of the infiltration bed was intended to rise to the level of the soil pits such that it would provide water to the trees. Additional information about the site and tree trench system can be found in earlier work involving this system [24-25].

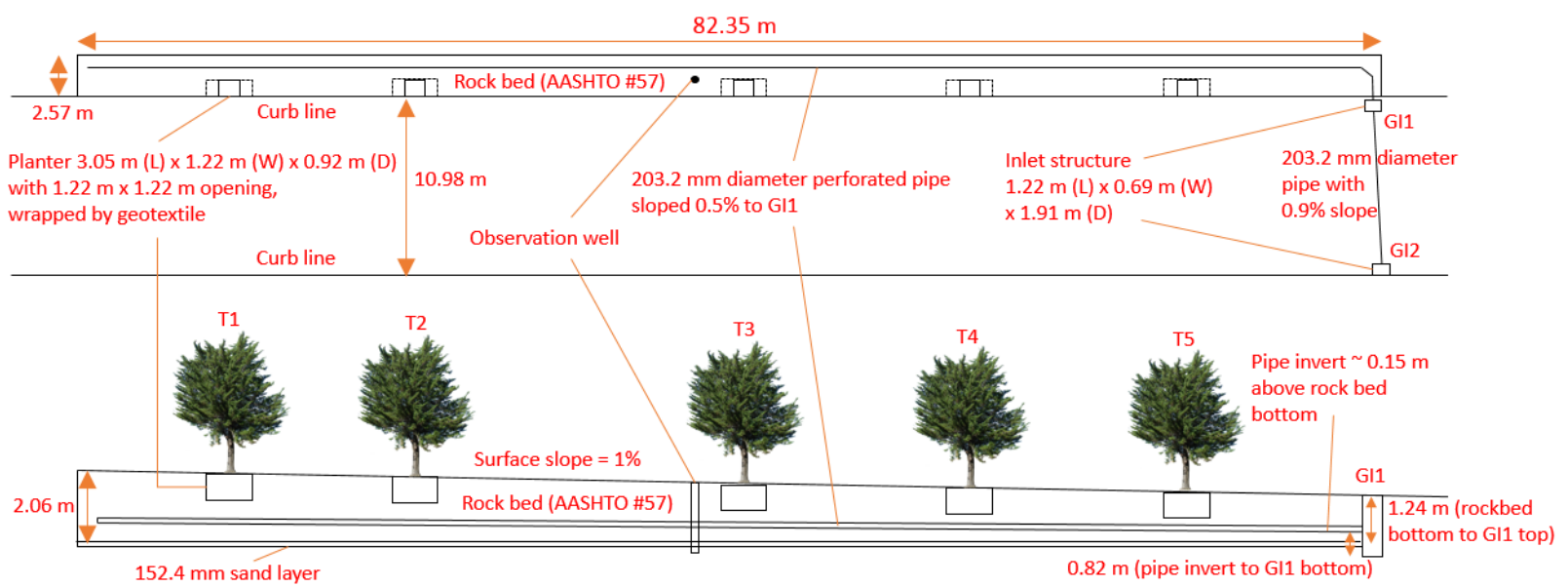

Figure 1. The green infrastructure system under investigation; plan view (top) and profile view (bottom). Reprinted from Tu and Traver [24].

\subsection{Hydrological characterization}

A time-series dataset of water depth in the trench was used to quantify the frequency that stormwater reached the bottom of each tree's soil pit. The dataset spanned March 2015 to April 2018, with data collected at 5 min intervals; 119 storms occurred during this period. A HOBO pressure transducer (Onset Computer Corporation, Bourne, USA) recorded water depth in the infiltration bed; it was set into an observation well in the center of the trench (Fig. 1). Volumetric soil moisture content $(\theta)$ was measured at $5 \mathrm{~min}$ intervals in each soil pit using HydraProbe sensors (Stevens Water Monitoring Systems, Portland, USA) located at $10 \mathrm{~cm}$ and $35 \mathrm{~cm}$ depth. Two additional sensors were installed at $60 \mathrm{~cm}$ in $\mathrm{T} 2$ and $\mathrm{T} 4$; the $60-\mathrm{cm}$ sensor in $\mathrm{T} 4$ was the deepest by elevation. A weather station installed at the site monitored precipitation and other meteorological conditions; details are provided in Tu and Traver [24]. 


\subsection{Plant water stress}

The response of tree water relations to varying soil moisture conditions was characterized from a dataset on mid-day leaf water potential $\left(\Psi_{\mathrm{md}}\right)$ and stomatal conductance $\left(\mathrm{g}_{\mathrm{s}}\right)$ collected in 2015. Procedures for data collection are described in detail elsewhere [25] but briefly, $\Psi_{\mathrm{md}}$ and $\mathrm{g}_{\mathrm{s}}$ were measured in each of the five trees between 1100-1300 h, 1-2 times per week from May through October. A leaf porometer (SC-1, METER Environment, Pullman, USA) was used to measure $\mathrm{g}_{\mathrm{s}}$ and a Scholander-type pressure chamber (PMS Instruments, Albany, USA) was used to measure $\Psi_{\mathrm{md}}$. Records of the times when each physiological data point was collected were used to extract soil moisture data from an imputed time series representing levels at the $35 \mathrm{~cm}$ depth. Pearson correlation statistics were used to quantify the strength of the relationship between each water relations variable and soil moisture levels.

\subsection{Simulated runoff test}

A simulated runoff test (SRT) was performed on 1 August 2017 to investigate tree and trench dynamics under relatively extreme inflow conditions. Runoff water was provided by a street hydrant connected to a flow meter and valve such that the release rate could be adjusted to increase the water depth gradually. Water was applied on the street surface so that it would flow towards the pair of inlets (Fig. 1) and enter the tree trench via the same pathway taken by runoff. The SRT began after a set of baseline measurements of tree performance was completed (see below) and proceeded for approximately 3.5 hours. Soil moisture, water depth, and associated hydrological data were collected throughout.

Trees' water-use responses to the SRT were determined using measurements of $\mathrm{g}_{\mathrm{s}}$. Measurements spanned five time periods: one immediately prior to the SRT, three during the SRT, and one the morning after the SRT. In addition to the five trees in the focal tree trench, a P. $\times$ acerifolia tree in an adjacent GI system of the same design (but that did not experience the SRT) was also measured to provide a reference for diurnal changes in $g_{s}$. To account for variation in $g_{s}$ within each tree's canopy, measurements were taken from at least three randomly-selected leaves from both exterior and interior portions of the canopy ( $n=6-14$ measurements per tree per period).

A statistical analysis was performed to determine how $g_{s}$ changed during the course of the SRT, if this differed from the tree in the adjacent trench, and if responses differed between species. A mixed-effects linear regression model was used; fixed effects included species identity, GI identity (i.e., SRT or non-SRT), canopy position (i.e., measurements taken in either the interior or exterior portion of the canopy), measurement period (a discrete variable with five levels), as well as all possible two-way interactions except GI identity $\times$ species (because data were only available for a single species from the non-SRT GI). A random effect for tree identity (discrete with 6 levels) was included to account for repeated measurements of individual trees. All hierarchically complete models were fit using maximum likelihood estimation via the lme4 library [26] in R version 3.6.0 [27]. Binary variables were coded \pm 0.5 and $\mathrm{g}_{\mathrm{s}}$ centered and divided by two standard deviations [28]. Model-averaged coefficients were then determined for all models with $\triangle \mathrm{AIC} c<4$; coefficients for terms not present in a model were taken to be zero for the purpose of averaging. This process yielded robust coefficients (denoted $\beta$ ) proportional to each term's effect on $g_{s}$, as well as their unconditional standard errors and 95\% confidence intervals [29]. The model term for the first period defined the intercept of the model, such that terms for periods 2-5 represented deviations from it.

\subsection{Hydrological modeling}

A hydrological model was used to evaluate the response of soil moisture to wetting by stormwater from the infiltration bed. The model was generated in HYDRUS-2D and simulated water movement in variably saturated and unsaturated soil media by solving the Richards equation [30]; it was parameterized for a vertical plane through the $\mathrm{T} 4$ soil pit such that it intersected the position of the $60-\mathrm{cm}$ soil moisture sensor (dashed line in Fig. 2). This location was selected because it allowed for a direct comparison to the empirical soil moisture dataset. In the model, all boundaries below the 
elevation corresponding to the highest water level reached (which occurred during the SRT) were designated as having "variable head" conditions. The remaining side walls were designated as "seepage faces" because the pits were surrounded by gravel subject to atmospheric pressure [31]. No flow was assumed at the top boundary. Water retention parameters of the soil in the tree pits were derived empirically using a pair of intact cores. Pressure potentials and their corresponding water content values were measured with a HYPROP and WP4C (METER Environment, Pullman, USA). Parameters were determined by fitting the van Genuchten function [32] to the combined datasets; parameter values from the two curves were averaged (Table 1). At the outset of model runs, soil moisture was set to match the value recorded by the soil moisture sensors $\left(0.16 \mathrm{~m}^{3} \mathrm{~m}^{-3}\right)$. The saturated hydraulic conductivity of the media was also used in the model, having been measured from the same cores using a KSAT device (METER Environment, Pullman, USA).

The geotextile was not simulated in the model. Given its permeability $\left(0.274 \mathrm{~cm} \mathrm{~s}^{-1}\right)$ and thickness $(0.15 \mathrm{~cm})$, even if the flow velocity through the geotextile was equal to the soil's saturated hydraulic conductivity $\left(0.296 \mathrm{~cm} \mathrm{~s}^{-1}\right)$, the head loss generated by the geotextile would have been negligible $(0.16$ $\mathrm{cm})$. If the geotextile had become partially clogged during its 4-year lifespan, the head loss would have been greater and the elevation of the actual wetting front would have been lower than observed, not higher [33].

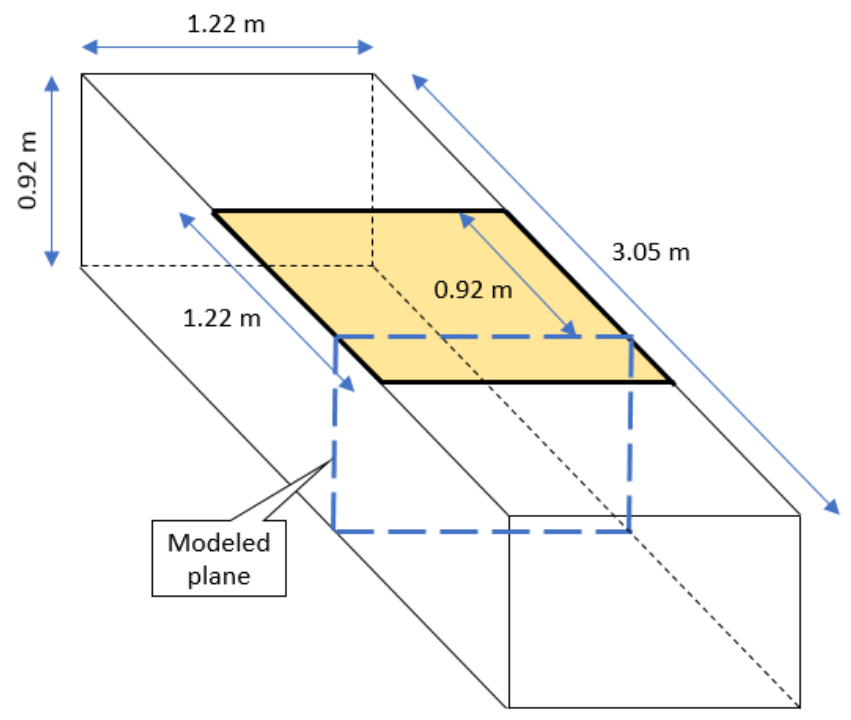

Figure 2. Schematic of a soil pit showing the location and orientation of the plane modeled in HYDRUS 2-D. The yellow square depicts the opening in the sidewalk for the tree while the blue dashed line depicts the modeled plane.

Table 1. Parameters of the engineered soil's water retention curve and saturated hydraulic conductivity as used in HYDRUS-2D

\begin{tabular}{cccc}
\hline Parameter & Unit & Meaning & Value \\
\hline $\mathrm{Q}_{\mathrm{r}}$ & $\mathrm{m}^{3} \mathrm{~m}^{-3}$ & Residual water content & 0.029 \\
$\mathrm{Q}_{\mathrm{s}}$ & $\mathrm{m}^{3} \mathrm{~m}^{-3}$ & Saturated water content & 0.479 \\
$\alpha$ & $\mathrm{cm}^{-1}$ & Air entry suction parameter & 0.040 \\
$\mathrm{n}$ & dimensionless & Pore size distribution parameter & 1.344 \\
$\mathrm{~K}_{\mathrm{s}}$ & $\mathrm{cm} \mathrm{min}-1$ & Saturated hydraulic conductivity & 0.296 \\
\hline
\end{tabular}




\section{Results}

\subsection{Hydrological characterization}

Of the 119 recorded storms between March 2015 and April 2018, 66 yielded enough water to be detectable in the infiltration bed. Excluding the SRT, none of these storms caused water to rise sufficiently high in the infiltration bed to reach the bottom of any tree pit (Fig. 3). The maximum observed water depth was associated with a $69 \mathrm{~mm}$ storm and caused water to rise to $0.63 \mathrm{~m}$. This was $0.03 \mathrm{~m}$ lower than the bottom of the T5 soil pit and $0.63 \mathrm{~m}$ lower than the bottom of the T1 soil pit.

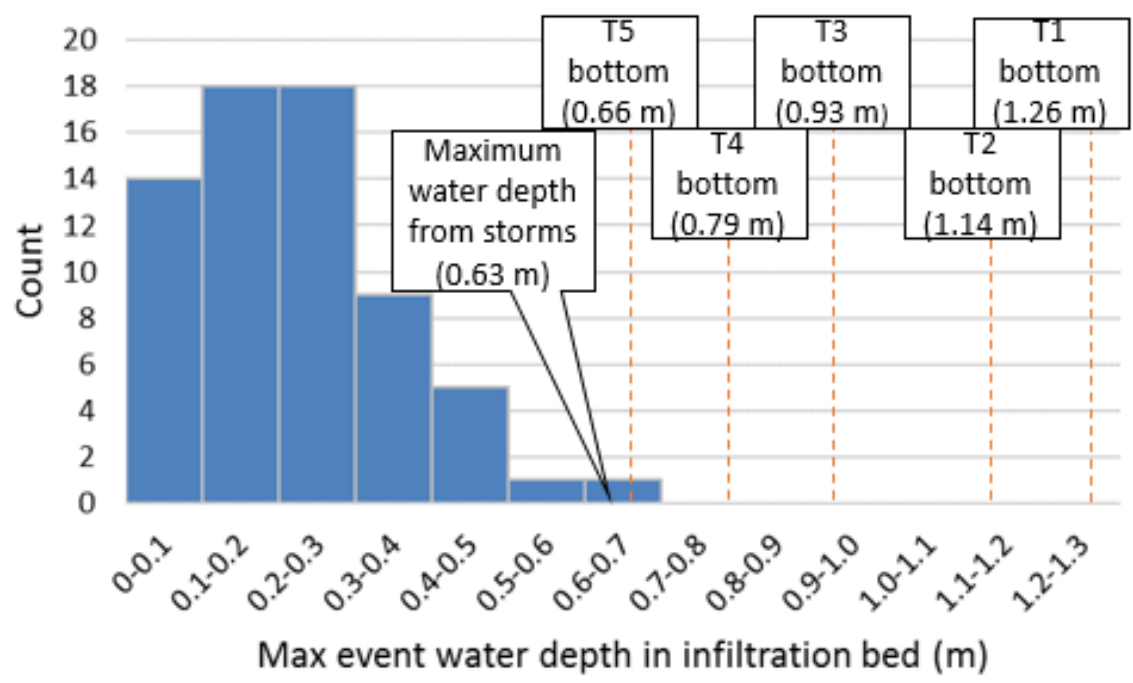

Figure 3. Distribution of maximum event water depth (natural storms only) in the tree trench's infiltration bed between March 2015 and April 2018.

\subsection{Plant water stress}

Both species exhibited less favorable leaf water potential as soil water declined (Fig. 4a). The relationship was approximately linear in both species, but the relationship was weaker for $P . \times$ acerifolia $(\beta=0.50)$ than for $A$. $\times$ freemanii $(\beta=0.66)$. Moreover, $\Psi_{\mathrm{md}}$ was below the level typically indicative of hydraulic damage to plant tissue $(-1.5 \mathrm{MPa})$ more frequently in $A$. $\times$ freemanii than in $P$. $\times$ acerifolia (39\% vs. $4 \%$ of measurements, respectively). A large portion of these observations occurred when $\theta$ was below $0.20 \mathrm{~m}^{3} \mathrm{~m}^{-3}$. Stomatal conductance varied weakly with soil moisture in $P$. $\times$ acerifolia $(\beta=0.24$; Fig. $4 \mathrm{~b})$; the relationship was slightly stronger for $A . \times$ freemanii $(\beta=0.34)$, especially when $\theta$ was below $0.20 \mathrm{~m}^{3} \mathrm{~m}^{-3}(\beta=0.54)$. 

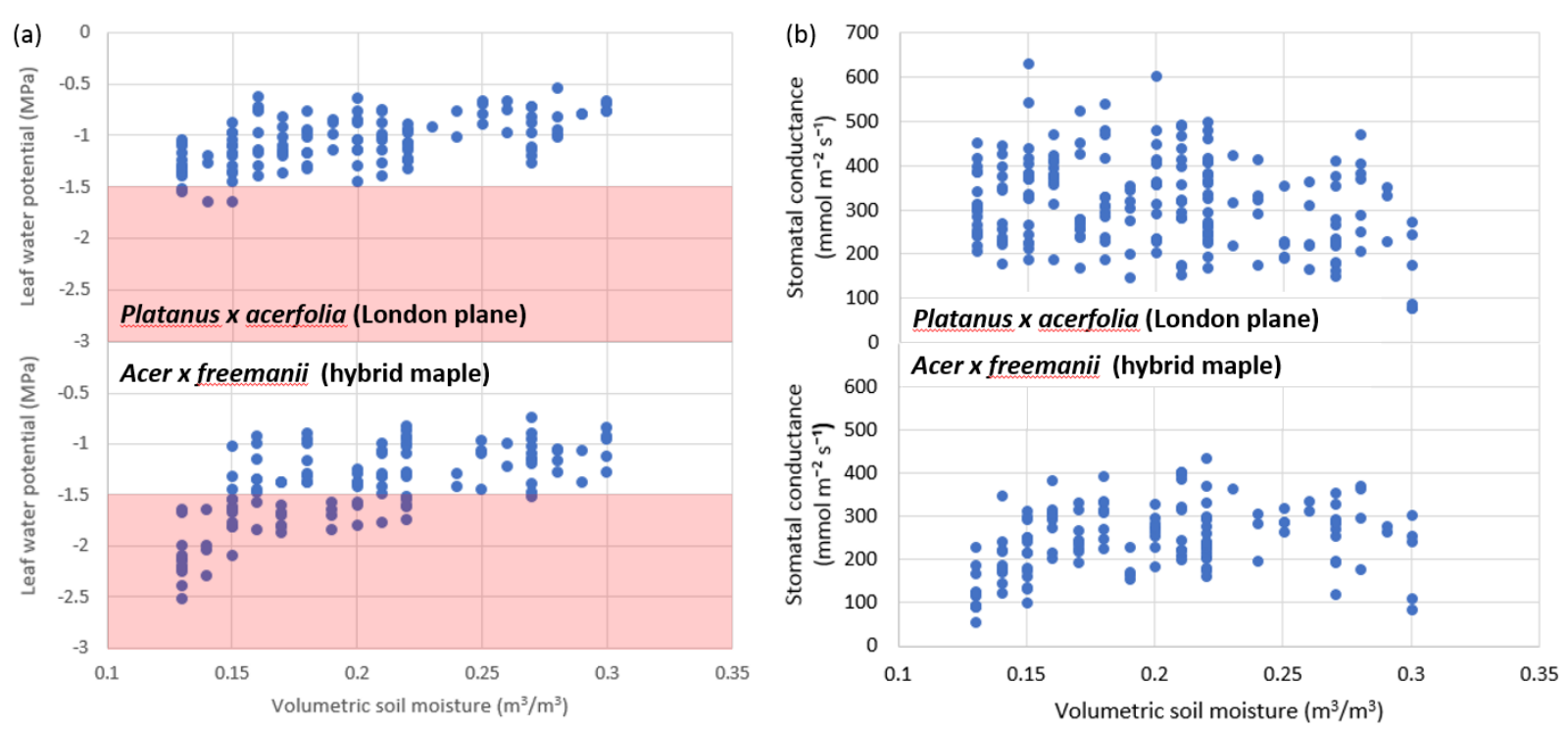

Figure 4. Relationship between soil moisture and (a) leaf water potential or (b) stomatal conductance for the two tree species investigated. The red shaded area denotes the water potential levels at which plant water stress typically occurs (>1.5 MPa [22]).

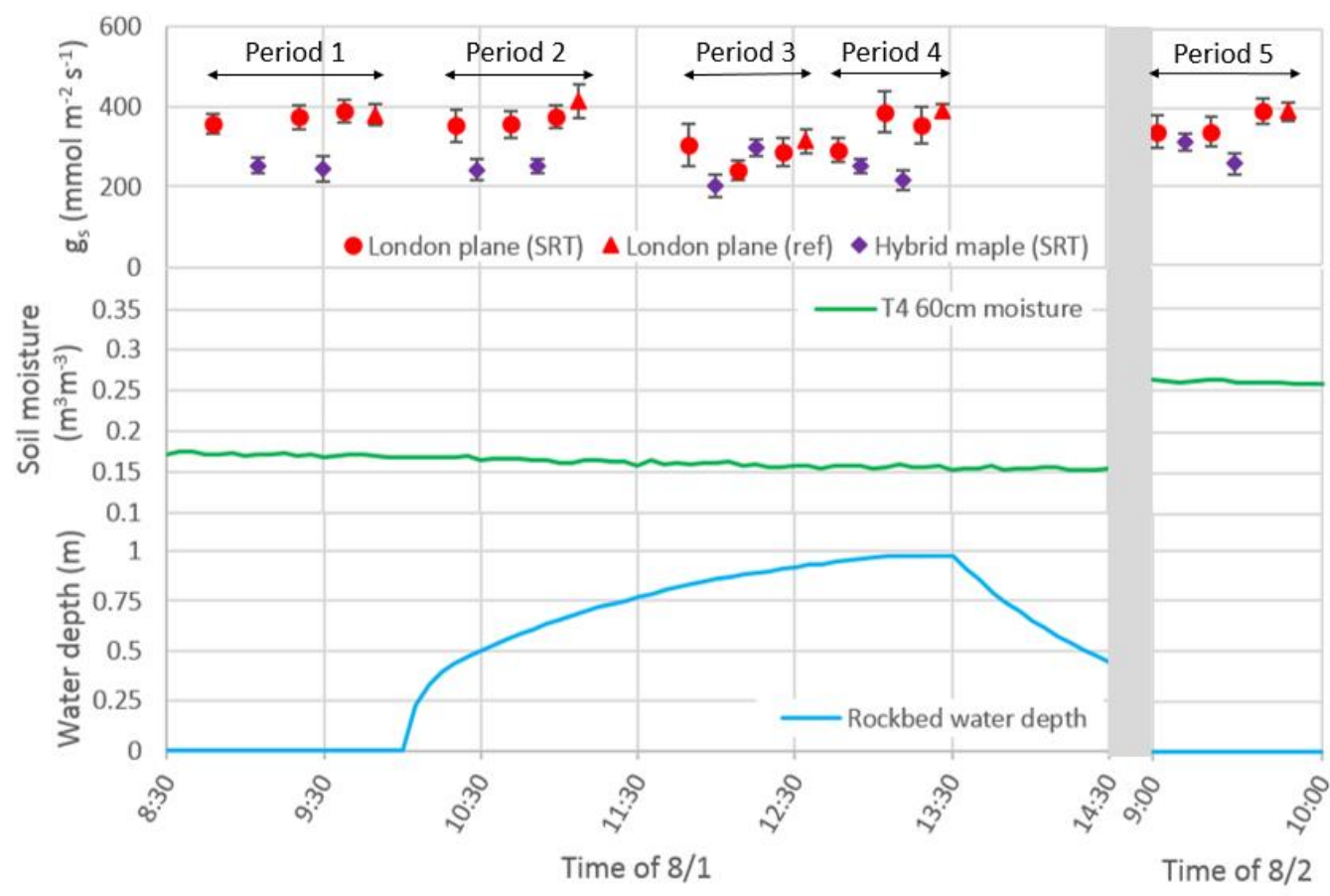

Figure 5. Data collected during and after the simulated runoff test. Points depict mean $( \pm$ SE) stomatal conductance $\left(g_{s}\right)$ across repeated measurements in each tree. SRT $=$ trees undergoing the simulated runoff test; Ref = reference trees.

\subsection{Simulated runoff test}

Tree-level means of $g_{s}$ remained between approximately 200 and $400 \mathrm{mmol} \mathrm{m} \mathrm{m}^{-2} \mathrm{~s}^{-1}$ during all measurement periods (Fig. 5); this was both the case for trees that did and did not experience the SRT. Statistical modeling showed that $g_{s}$ in the non-SRT GI was marginally greater $(\beta=-0.144$ with 95\% CI including zero; Table 2), likely because the non-SRT GI only contained $P . \times$ acerifolia. The greatest source of variation in $g_{s}$ was species identity, with $P . \times$ acerifolia having substantially greater rates than $A . \times$ freemanii $(\beta=0.427)$. Canopy position was the second-strongest source of variation in 
$g_{s}$, with leaves from the exterior portions of canopies having greater $g_{s}$ than those from canopy interiors $(\beta=0.375)$, as expected [34].

The primary case in which $g_{s}$ differed among measurement periods was a decline from baseline during Period 3 (11:30-12:30 $\mathrm{h} ; \beta=-0.176$ for the main effect). The change was potentially greater for $P . \times$ acerifolia $(\beta=-0.251$ for the interaction), though the coefficient's $95 \%$ CI included zero. This decline was likely a result of trees restricting water loss in response to high evaporative demand during the middle part of the day, a phenomenon that has been observed in many studies previously [35]. Rates returned to baseline in Period $4(\beta=-0.038)$, at least for three of the four $P . \times$ acerifolia trees (including that in the non-SRT GI). There was also some evidence that mean $g_{s}$ increased over baseline the following day (Period $5 ; \beta=0.098$ ) with $A . \times$ freemanii contributing disproportionately to this increase $(\beta=-0.135)$.

Table 2. Statistical modeling results for a linear mixed-effects model of stomatal conductance. Bold depicts model terms with relatively strong influence $(|\beta|>0.1)$. Only terms in models with $\Delta \mathrm{AIC}_{\mathrm{c}}<$ 4 are shown

\begin{tabular}{cccc}
\hline Model term & Coefficient $(\boldsymbol{\beta})$ & SE & $\mathbf{9 5 \%}$ CI \\
\hline Period 2 & 0.019 & 0.069 & $(-0.116,0.155)$ \\
Period 3 & -0.176 & 0.075 & $(-0.324,-0.029)$ \\
Period 4 & -0.038 & 0.070 & $(-0.176,0.099)$ \\
Period 5 & 0.098 & 0.070 & $(-0.040,0.236)$ \\
Canopy position & -0.375 & 0.055 & $(-0.483,-0.268)$ \\
Species & 0.427 & 0.100 & $(0.232,0.622)$ \\
GI identity & -0.144 & 0.075 & $(-0.290,0.003)$ \\
Period 2 x Species & 0.022 & 0.119 & $(-0.211,0.255)$ \\
Period 3 x Species & -0.251 & 0.200 & $(-0.643,0.140)$ \\
Period 4 x Species & 0.002 & 0.119 & $(-0.232,0.236)$ \\
Period 5 x Species & -0.135 & 0.146 & $(-0.421,0.151)$ \\
Canopy position x Species & -0.205 & 0.110 & $(-0.420,0.010)$ \\
Canopy position x GI identity & -0.016 & 0.068 & $(-0.149,0.118)$ \\
\hline
\end{tabular}

\subsection{Hydrological modeling}

The HYDRUS model indicated that, when the gravel bed's water level rose to the highest point it reached during the SRT (and therefore during the lifetime of the GI system), the soil media was near saturation $\left(\theta=0.450-0.479 \mathrm{~m}^{3} \mathrm{~m}^{-3}\right)$ to approximately $10 \mathrm{~cm}$ depth (Fig. 6). Above the saturation zone, $\theta$ exhibited a sharp vertical gradient through an additional, approximately $10 \mathrm{~cm}$-thick capillary zone, decreasing from near saturation to $0.16 \mathrm{~m}^{3} \mathrm{~m}^{-3}$. The effect of water contacting the soil pit, therefore, had no effect at the level of the $60-\mathrm{cm}$ soil moisture sensor; $\theta$ modeled at the sensor varied minimally during the simulation, mimicking the empirical time series (Fig. 5). 


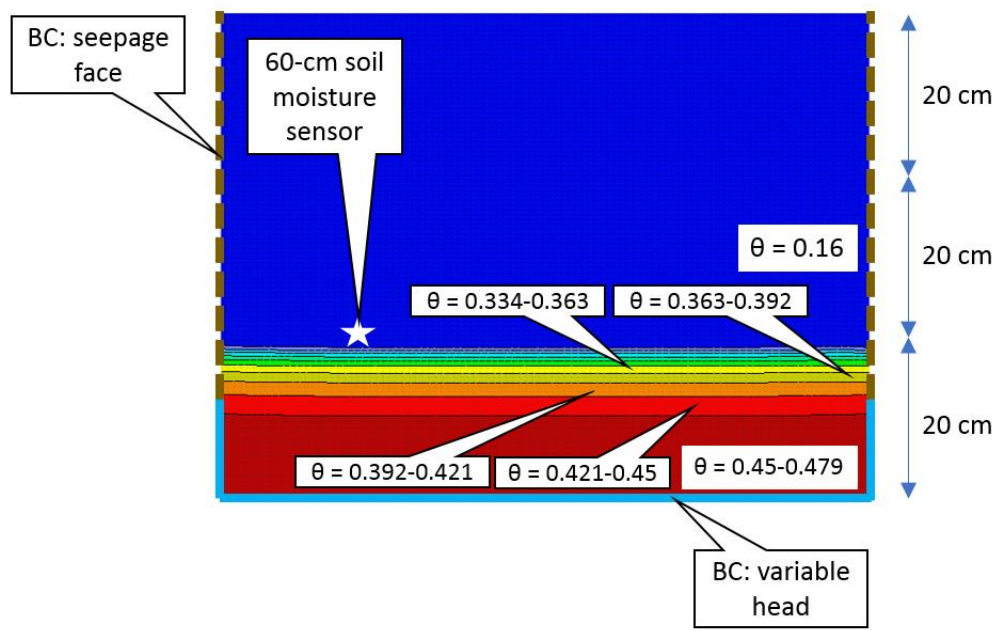

Figure 6. Modeled soil moisture $(\theta)$ in the deepest soil pit when the water level in the GI was highest $(13: 30 \mathrm{~h})$. Variable head boundary conditions are shown as a light blue line while seepage face boundary conditions are shown as a dashed brown line.

\section{Discussion}

\subsection{Overdesign \& Plant Water Stress}

The tree trench system on which this study was based was unquestionably overdesigned with respect to its capacity to store water. Water in the infiltration bed did not reach the bottom of even the lowest-elevation soil pit during any of the natural storm events that the system experienced in the four-year period considered. While this had no ill effects on the system's primary function of water removal, it hydraulically isolated the soil pits from the infiltration bed. Therefore, soil media received water primarily via direct reception of rainfall, i.e., through the $1.22 \times 1.22 \mathrm{~m}$ openings in the sidewalk surface (Fig. 7). Moreover, the hydraulic properties of the media compounded the effects of overdesign. Although water did reach the bottom of the modeled soil pit during the SRT, the media exerted insufficient capillary force to retain an appreciable amount of water at pressure potentials over which it would be accessible to plants (-33 to $-1500 \mathrm{kPa}$ [36]) and was therefore rapidly lost to the underlying gravel bed. This can likely be attributed to the high sand content of the media $(87.6 \%)$, with the implication that stormwater entering from the sidewalk would be similarly poorly retained. In combination, the absence of the intended subsurface water supply, restricted surface inputs, and rapidly-draining media meant that soil pits contained far less than the intended amount of soil water during rain-free periods.

The implications of limited water availability in soil pits to the trees were strongly speciesdependent. In the case of $A . \times$ freemanii, water stress (low $\Psi_{\mathrm{md}}$ ) occurred frequently through the growing season, especially when soil water availability was reduced, and was presumably the factor responsible for strong restrictions in water use. Unless mitigated by other factors, this phenomenon could be expected to occur in many overdesigned GI systems, ultimately leading to poorer tree health and mortality [37]. In contrast to A. $\times$ freemanii, $P . \times$ acerifolia exhibited water stress infrequently through the growing season, likely contributing to its ability to maintain high $g_{s}$. In addition, the rebound in $g_{s}$ for $P . \times$ acerifolia during Period 4 of the SRT is also consistent with it responding to an increase in water availability, as weather conditions (notably vapor pressure deficit) had not changed since the decline that occurred during Period 3.

A parsimonious explanation for the contrasting water relations of the two species is that $P . \times$ acerifolia had an alternative subsurface water source that buffered it from changes in soil moisture in tree pit soil, while $A . \times$ freemanii relied almost exclusively on soil water within the soil pits themselves. Evidence that $P . \times$ acerifolia had gained access to water below, or possibly at the bottom of, the infiltration bed includes direct observations of roots in the distribution pipe, reports of deep-rooting in other Platanus species, and the larger size of P. $\times$ acerifolia trees. Specifically, roots were evident 
along nearly the full length of the distribution pipe in videos recorded during a maintenance investigation (Fig. 8). These observations confirm that roots had extended beyond the primary impediment, namely the geotextile lining the soil pits, though $A . \times$ freemanii roots may have been among those observed. The inference that most of the deeply-proliferated roots were from $P . \times$ acerifolia (aside from its more consistent water status) derives from prior observations of Platanus spp. roots extending below $2 \mathrm{~m}$ [38-39] in combination with the fact that $P . \times$ acerifolia stems and canopies were appreciably larger than those of $A . \times$ freemanii (Fig. 7); positive associations between rooting depth and the above-ground size of woody plants are common in water-limited systems [40]. Moreover, a study of street trees found that the growth of Platanus species was accelerated in sandy soil while that of Acer species was hindered [41]; it is likely that a similar pattern arose in the focal trench given the high sand content of its soil pits. The fact that $A . \times$ freemanii responded minimally to the SRT but increased $g_{s}$ following the overnight rain event also suggests that soil pits were its dominant source of water.

\subsection{Implications for Design}

Ideally, vegetated GI systems would be deliberately designed to minimize plant water stress while still meeting stormwater management goals. This is likely to be less difficult in cases where vegetation is smaller in stature and therefore has lower water requirements than do trees, though trees are preferred in many settings given their aesthetic and ability to provide services like shade [42]. Trees' rates of water use are also typically greater than those of smaller-stature plants [19, 43], enhancing their utility in GI. In designing GI systems for which trees are desired but their soil pits are at risk of hydraulic isolation (notably, tree trenches), the results of this study suggest that several modifications to typical designs could help to minimize the frequency and intensity of water stress events.

First, designers should restrict overdesign such that water captured in infiltration beds during small to moderate storms thoroughly wets the soil provided to plants. In most cases, achieving an appropriate distribution of water depths through time would entail carefully optimizing design parameters (such as catchment depth), e.g., to account for exfiltration, rather than using static sizing [44]. Such efforts may be particularly important when the infiltration capacity of the native soil is moderate or greater (such as with the focal trench; Fig. 9). While restricting the depth or other dimensions of infiltration beds may reduce the capacity for stormwater retention, this is likely to be problematic only rarely during the lifespan of the GI system, such as when large storms occur in succession [45]. In tree trenches, the ability of stormwater to exfiltrate through side walls appears to further reduce the probability of overflow [46-47], suggesting that trenches could be much shallower than those calculated under the assumption that exfiltration occurs strictly through the bottom surface. Accordingly, it may be possible to make simple adjustments to the dimensions of infiltration beds that increase plant available water further into rain-free periods, ultimately improving plant health and survival.

Second, the capacity of soil media to draw water upward by capillary force should be considered carefully. If insufficient, a situation like that observed during this study's SRT can arise, in which most water accumulated at the bottom of the soil pit and the capillary zone was quite narrow $(10 \mathrm{~cm}$; Fig. 6). Using media with a greater capacity for capillary uptake than that used in the focal trench could significantly increase water retention in the plant-available range and decrease the frequency and intensity of water stress events. Adjusting clay and organic matter components of soil media may be inexpensive means of achieving this, though amendments such as water-absorbing polymers and biochar could also be considered. Increasing the amount of stormwater entering soil pits from the sidewalk surface (e.g., using porous pavement, curb cuts, or shaping sidewalk surfaces to direct water to soil pits) could also help to reduce the effects of hydraulic isolation.

Third, tree species and cultivars should be selected that are suited to the unique hydrologic regime of the GI system; this may be a somewhat different set than is suitable for non-GI street trees. Choosing species after an empirical evaluation of hydrologic conditions in a GI made during installation could minimize the chances of a mismatch, though this may not be possible in many 
cases. Another important aspect of species selection in tree trench settings may be whether the proliferation of roots outside soil pits can be tolerated or if it should be avoided. If root proliferation can be tolerated, it may be possible to select species likely to find alternative water sources before the trees grow to a size where hydraulic isolation imposes severe physiological stress. Otherwise, it may be beneficial to select species that can tolerate limited water availability or to enact the abovementioned strategies of increasing soil water availability. Using root barriers may also be particularly important in these cases.

\section{Conclusions}

Whether done inadvertently or deliberately, overdesign can be an issue in GI systems that are intended to deliver water to plants by raising the level of stored water high enough to contact overlying soil. In such systems, the frequency that soils are wetted is likely to be lower than intended and, in the periods between rain events, plants may experience moderate to severe water stress. A number of other factors can influence the dynamics of this process and could potentially be attended to during the design phase (e.g., soil water retention properties and the availability of pathways for water to contact soils directly). Notably, even among street trees and common landscaping plants, taxa may have extremely different responses to water shortages due to functional traits like rooting depth. In combination with advances in large-scale planning methods [48], efforts to improve GI's ability to support vegetation at the site-scale could substantially expand the performance of GI systems both in managing stormwater and in greening cities.

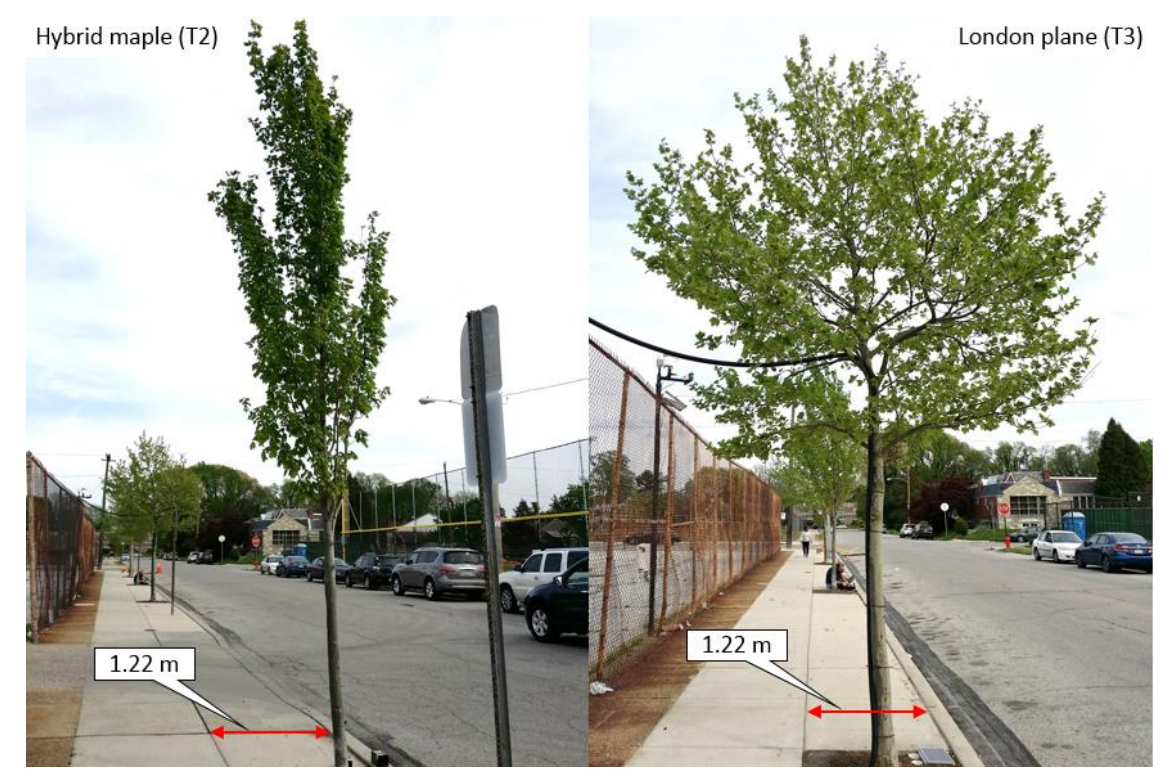

Figure 7. Canopies of A. × freemanii (T2) and P. × acerifolia (T3) in April 2017. 


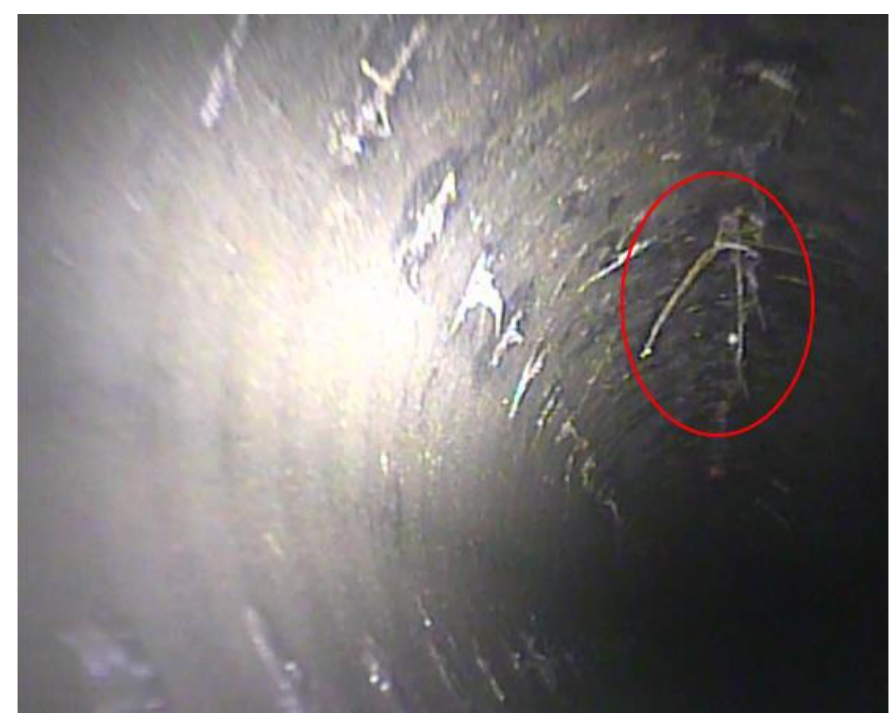

Figure 8. Root penetration into the distribution pipe during subsurface cleaning in June 2016.

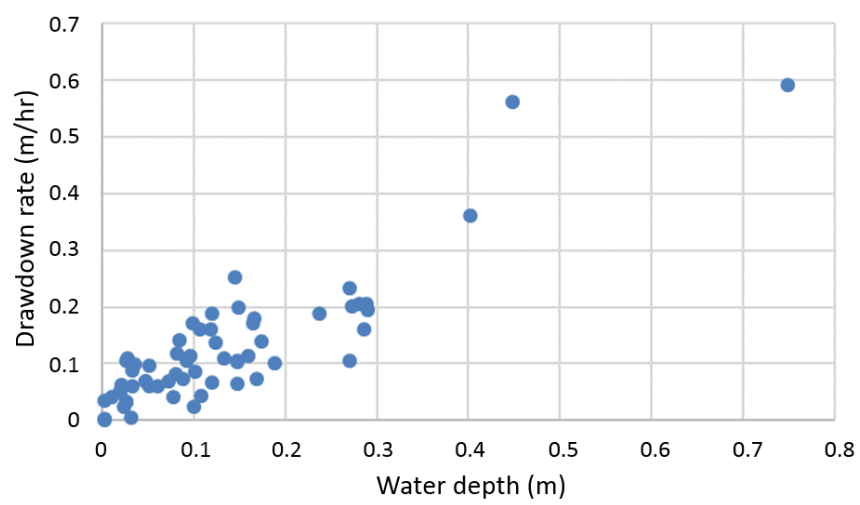

Figure 7. Comparison of maximum drawdown rate vs. water depth in the infiltration bed of all events including the simulated runoff test.

Author Contributions: Min-cheng Tu: Conceptualization, Methodology, Software, Formal analysis, Investigation, Writing-Original draft preparation, Visualization Joshua Caplan: Conceptualization, Methodology, Software, Formal analysis, Investigation, Writing-Original draft preparation Sasha Eisenman: Methodology, Resources, Writing-review and editing, Supervision, Project administration, Funding acquisition Bridget Wadzuk: Writing - review and editing, Project administration, Funding acquisition. All authors have read and agreed to the published version of the manuscript.

Funding: This research was supported by a grant from the U.S. Environmental Protection Agency's Science to Achieve Results (STAR) program (\#83555601).

Acknowledgments: Support from the Philadelphia Water Department (in particular, Stephen White and Chris Bergerson) was key to the success of this work. We are grateful to Cara Albright for the design and installation of onsite instrumentation. We also thank Russell Galanti, Stuart Olshevski, Alyssa Chattin, and Wiley Kollar for collecting physiological data. Comments from John Ferris on an earlier draft of this work are also appreciated.

Conflicts of Interest: The authors declare no conflict of interest.

\section{References}

1. Botting, J.; Bellette, K. Stormwater Pollution Prevention - Code of Practice for Local, State, and Federal Government; Environment Protection Authority: Adelaide, SA, Australia, 1998.

2. Roe, M.; Mell, I. Negotiating Value and Priorities: Evaluating the Demands of Green Infrastructure Development. J. Environmental Planning and Management. 2012, 56(5), 650-673.

3. United States Environmental Protection Agency. National Pollutant Discharge Elimination System (NPDES). Available online: https://www.epa.gov/npdes (accessed on 17 May 2019). 
4. Tu, M.-c.; Smith, P. Modeling Pollutant Buildup and Washoff Parameters for SWMM Based on Land Use in a Semiarid Urban Watershed. Water Air Soil Pollut. 2018, 229, 121, doi: 10.1007/s11270-018-3777-2

5. Ahiablame, L.M.; Engel, B.A.; Chaubey, I. Effectiveness of Low Impact Development Practices: Literature Review and Suggestions for Future Research. Water, Air, \& Soil Pollution. 2012, 223(7), 4253-4273.

6. Buccola, N.; Spolek, G. A Pilot-scale Evaluation of Greenroof Runoff Retention, Detention, and Quality. Water, Air, E Soil Pollution. 2011, 216(1-4), 83-92.

7. Lucas, W.C.; Greenway, M. Hydraulic Response and Nitrogen Retention in Bioretention Mesocosms with Regulated Outlets: Part I - Hydraulic Response. Water Environ. Res. 2011, 83, 692-702.

8. Yang, B.; Li, S. Green Infrastructure Design for Stormwater Runoff and Water Quality: Empirical Evidence from Large Watershed-scale Community Developments. Water. 2013, 5(4), 2038-2057.

9. Tu, M.-c.; Traver, R.G. Water Table Fluctuation from Green Infrastructure Sidewalk Planters in Philadelphia, Pennsylvania. J. Irrig. Drain. Eng. 2019, 145(2), 05018008, doi: 10.1061/(ASCE)IR.19434774.0001369

10. Rejskova, A.; Cizkova, H.; Brom, J. Transpiration, Evapotranspiration and Energy Fluxes in a Temperate Wetland Dominated by Phalaris Arundinacea under Hot Summer Conditions. Ecohydrology. 2012, 5, $19-27$.

11. DiGiovanni, K.; Montalto, F.; Gaffin, S. Applicability of Classical Predictive Equations for the Estimation of Evapotranspiration from Urban Green Spaces: Green Roof Results. J. Hydrol. Eng. 2013, 18(1), 99-107.

12. Wadzuk, B.M.; Schneider, D.; Feller, M. Evapotranspiration from a Green-roof Storm-water Control Measure. J. Irrig. Drain. Eng. 2013, 139(12), 995-1003.

13. Wadzuk, B.M.; Hickman, J.M.; Traver, R.G. Understanding the Role of Evapotranspiration in Bioretention: Mesocosm Study. J. Sustainable Water Built Environ. 2015, 1(2): 04014002.

14. Zaremba, G.J.; Traver, R.G.; Wadzuk, B.M. Impact of Drainage on Green Roof Evapotranspiration. J. Irrig. Drain Eng. 2016, 142(7), 04016022.

15. Hess, A.; Wadzuk, B.; Welker, A. Evapotranspiration in Rain Gardens Using Weighing Lysimeters. J. Irrig. Drain Eng. 2017, 143(6), 04017004.

16. Wang, Y.; Bakker, F.; de Groot, R. Effect of Ecosystem Services Provided by Urban Green Infrastructure on Indoor Environment: A Literature Review. Building and Environment. 2014, 77, 88-100.

17. Vrban, S.; Wang, Y.; McBean, E.A. Evaluation of Stormwater Infrastructure Design Storms Developed Using Partial Duration and Annual Maximum Series Models. J. Hydrol. Eng. 2018, 23(12), 04018051.

18. Brown, R.A.; O'Connor, T.P.; Borst, M. Divergent Vegetation Growth Patterns Relative to Bioinfiltration Unit Size and Plant Placement. J. Sustainable Water Built Environ. 2015, 1(3), 04015001.

19. Baldocchi, D.; Xu, L.; Kiang, N. How Plant Functional-type, Weather, Seasonal Drought, and Soil Physical Properties Alter Water and Energy Fluxes of an Oak-grass Savanna and an Annual Grassland. Agriculture and Forest Meteorology. 2004, 123, 13-39.

20. Reece, C.F.; Riha, S.J. Role of Root Systems of Eastern Larch and White Spruce in Response to Flooding. Plant, Cell and Environment. 1991, 14, 229-234.

21. Bouda, M.; Brodersen, C.; Saiers, J. Whole Root System Water Conductance Responds to Both Axial and Radial Traits and Network Topology over Natural Range of Trait Variation. J. Theor. Biol. 2018, 456, 49-61.

22. Lambers, H.; Chapin III, F.S.; Pons, T.L. Plant Physiological Ecology; Springer, New York, New York, U.S.A., 1998.

23. Flexas, J.; Medrano, H. Drought-inhibition of Photosynthesis in C3 Plants: Stomatal and Non-stomatal Limitations Revisited. Ann. Bot. 2002, 89, 183-189.

24. Tu, M.-c.; Traver, R.G. Clogging Impacts on Distribution Pipe Delivery of Street Runoff to an Infiltration Bed. Water. 2018, 10(8), 1045, doi: 10.3390/w10081045

25. Caplan, J.S.; Galanti, R.C.; Olshevski, S. Water Relations of Street Trees in Green Infrastructure Tree Trench Systems. Urban Forestry and Urban Greening. 2019, 41, 170-178.

26. Bates, D.; Maechler, M.; Bolker, B. LME4: Linear Mixed-effects Models Using 'Eigen' and S4. Available online: https://cran.r-project.org/web/packages/lme4/index.html (accessed on 8 January 2019).

27. R Foundation for Statistical Computing. R: A Language and Environment for Statistical Computing. Available online: https://www.R-project.org/ (accessed on 10 January 2020)

28. Gelman, A. Scaling Regression Inputs by Dividing by Two Standard Deviations. Statistics in Medicine. 2008, 27, 2865-2873.

29. Grueber, C.E.; Nakagawa, S.; Laws, R.J. Multimodel Inference in Ecology and Evolution: Challenges and Solutions. J. Evol. Biol. 2011, 24, 699-711. 
30. PC-PROGRESS. HYDRUS 2D/3D for Windows. Available online: https://www.pcprogress.com/en/Default.aspx?hydrus-3d (accessed on 10 January 2020)

31. Ebrahimian, H.; Noory, H. Modeling Paddy Field Subsurface Drainage Using HYDRUS-2D. Paddy Water Environ. 2014, 13(4), 477-485.

32. van Genuchten MT. A Closed-form Equation for Predicting the Hydraulic Conductivity of Unsaturated Soils. Soil Sci. Soc. of America J. 1980, 44: 892-898.

33. Veylon, G., Stoltz, G., Meriaux, P. Performance of Geotextile Filters After 18 Years' Service in Drainage Trenches. Geotextiles and Geomembranes. 2016, 44(4), 515-533.

34. Campbell, R.J.; Marini, R.P.; Birch, J.B. Canopy Position Affects Light Response Curves for Gas Exchange Characteristics of Apple Spur Leaves. J. Amer. Soc. Hort. Sci. 1992, 117(3), 467-472.

35. Zhang, Y.-j.; Meinzer, F.C.; Qi, J.-h. Midday Stomatal Conductance Is More Related to Stem rather than Leaf Water Status in Subtropical Deciduous and Evergreen Broadleaf Trees. Plant, Cell E Environment. 2013, 36, 149-158.

36. Tolk, J.A. Plant Available Soil Water. Encyclopedia of Water Science. Marcel-Dekker: New York, NY, USA, 2003; pp 669-672.

37. Varone, L.; Ribas-carbo, M.; Cardona, C. Stomatal and Non-stomatal Limitations to Photosynthesis in Seedlings and Saplings of Mediterranean Species Pre-conditioned and Aged in Nurseries: Different Response to Water Stress. Environmental and Experimental Botany. 2012, 75, 235-247.

38. Biswell, H. H. Effects of Environment upon the Root Habits of Certain Deciduous Forest Trees. Botanical Gazette. 1935, 96(4), 676-708.

39. Sprackling, J. A.; Read, R. A. Tree Root Systems in Eastern Nebraska. Nebraska Conservation Bulletin. 1979, 37.

40. Schenk, H.J.; Jackson, R.B. Rooting Depths, Lateral Root Spreads and Below-ground/Above-ground Allometries of Plants in Water-limited Ecosystems. J. Ecology. 2002, 90(3), 480-494.

41. Bühler, O.; Kristoffersen, P.; Larsen, S.U. Growth of Street Trees in Copenhagen with Emphasis on the Effect of Different Establishment Concepts. Arboriculture \& Urban Forestry. 2007, 33(5), 330-337.

42. Todorova, A.; Asakawa, S.; Aikoh, T. Preferences for and Attitudes towards Street Flowers and Trees in Sapporo, Japan. Landscape and Urban Planning. 2004, 69, 403-416.

43. Santiago, L.S.; Wright, S.J. Leaf Functional Traits of Tropical Forest Plants in Relation to Growth Form. Funct. Ecol. 2007, 21, 19-27.

44. De Paola, F.; Giugni, M.; Pugliese. Optimal Design of LIDs in Urban Stormwater Systems Using a Harmony-Search Decision Support System. Water Resources Management. 2018, 32, 4933-4951.

45. Wadzuk, B.M.; Lewellyn, C.; Lee, R. Green Infrastructure Recovery: Analysis of the Influence of Back-toback Rainfall Events. J. Sustainable Water Built Environ. 2017, 3(1), 04017001.

46. Emerson, C.H.; Wadzuk, B.M.; Traver, R.G. Hydraulic Evolution and Total Suspended Solids Capture of an Infiltration Trench. Hydrol. Process. 2010, 24, 1008-1014, doi:10.1002/hyp.7539.

47. Winston, R.J.; Dorsey, J.D.; Hunt, W.F. Quantifying Volume Reduction and Peak Flow Mitigation for Three Bioretention Cells in Clay Soils in Northeast Ohio. Sci. Total Environ. 2016, 553, 83-95.

48. De Paola, F.; Giugni, M.; Pugliese, F.; Romano, P. Optimal Design of LIDs in Urban Stormwater Systems Using a Harmony-Search Decision Support System. Water Resour. Manage. 2018, 32, 4933-4951, doi:10.1007/s11269-018-2064-8. 